\title{
Monoclonal Antibodies for the Identification of New World Leishmania Species
}

\author{
Gabriel Grimaldi Jr, Diane McMahon-Pratt ${ }^{*}$
}

\author{
Departamento de Imunologia, Instituto Oswaldo Cruz, Av. Brasil 4365, 21045-900 Rio de Janeiro, RJ, Brasil \\ *Department of Epidemiology and Public Health, Yale University School of Medicine, P.O. Box 3333, \\ New Haven, CT, 06510, USA
}

\begin{abstract}
Monoclonal antibodies specific for selected species complexes of Leishmania have been employed for the characterization of several representative strains of Leishmania isolated from different hosts and localities in the Americas. In the past 15 years, data have been accumulated concerning (i) the specificities of a number of these monoclonal antibodies and (ii) the antigenic variation (level of the expressed antigenic determinants) occurring among New World Leishmania species or strain variants as recognized by the monoclonal antibodies. This report is an attempt to summarize in brief the data accumulated to date on these points and to indicate the directions for future applications of these specific monoclonal antibodies for identification of leishmanial isolates.
\end{abstract}

Key words: Leishmania - serodemes - monoclonal antibodies - radioimmune binding assay - immunotaxonomy

Monoclonal antibodies have been employed extensively for the identification of Leishmania species, development of diagnostic tests, investigation of molecules associated with parasite virulence and/or pathogenicity, and in the characterization of defined leishmanial antigens that should be able to produce immunoprotection against human leishmaniasis following vaccination (reviewed in Grimaldi \& Tesh 1993).

Parasitic protozoa of the genus Leishmania (Kinetoplastida: Trypanosomatidae) are a biologically diverse group of microorganisms (Lainson $\&$ Shaw 1987). Taxonomic studies of Leishmania isolates from the New World indicate tremendous diversity within this genus (Cupolillo et al. 1994). A number of new Leishmania species have been described recently from sylvan areas of the Neotropics (Silveira et al. 1987, Lainson et al. 1989, Lainson \& Shaw 1989, Kreutzer et al. 1991, Grimaldi et al. 1992, Yoshida et al. 1993). Some other taxonomically distinct taxa, isolated from wild mammals and vectors in the Brazilian Amazon Region, have also been described as unnamed new species (Lainson \& Shaw 1987, Grimaldi et al. 1989, 1991). Much of this recent information on the epidemiology of the various New World Leishmania has been made through the application of techniques employing specific monoclonal antobodies as well as other molecular criteria for identifying and classifying leishmanial field isolates in comparison with standard reference strains (Saravia et al. 1985, Grimaldi et al. 1987, 1989,

Recived 12 April 1995

Accepted 28 June 1995
1991, 1992, Aguilar et al. 1989, Yoshida et al. 1990, Barral et al. 1991, Darce et al. 1991, Falqueto et al. 1991, Hashiguchi et al. 1991, Kreutzer et al. 1991, Ponce et al. 1991, BonfanteGarrido et al. 1992).

In order to determine a crosspanel of monoclonal antibodies suitable for parasite (species) identification, the WHO Special Programme for Research and Training on Tropical Diseases (TDR), the Pan American Health Organization (PAHO) and the Academia de Ciencias de America Latina, jointly organized two meetings in Washington, D.C. (February 1993) and Cali, Colombia (December 1993). Based upon the double blinded testing of Leishmania monoclonal antibodies (99), fourteen monoclonal antibodies were selected and recommended for general use in the identification of Leishmania species. Here we discuss the reactivities of some of these antibodies with Leishmania group- and species-specific antigens.

\section{MATERIALS AND METHODS}

Serodeme analysis using monoclonal antibodies - The monoclonals that have been used for characterization and identification of leishmanial isolates are listed elsewhere (Grimaldi et al. 1987, 1991, Hashiguchi et al. 1991, Kreutzer et al. 1991, Bonfante-Garrido et al. 1992). These monoclonals that distinguish both New World and Old World species of Leishmania were produced as reported previously (McMahon-Pratt \& David 1981, McMahon-Pratt et al. 1982, 1985, 1986, Jaffe \& McMahon-Pratt 1983, Jaffe et al. 1984, Pan \& McMahon-Pratt 1988) according to the method of Kohler and Milstein (1975) as modified by Kennett et al. (1978). Characterization of the 
Leishmania was performed with an indirect radioimmune binding assay (RIA) using whole parasite lysates as antigen. The technique has been described in detail before (Grimaldi et al. 1987). A subsample of the leishmanial stocks were also analyzed by indirect immunofluorescence (McMahon-Pratt et al. 1986) or ELISA assays (Jaffe \& McMahon-Pratt 1987) using the monoclonal antibodies.

Leishmania - Over the past 15 years, we have collected and characterized, by species-specific monoclonal antibodies and RIA, a large panel of leishmanial parasites. The results with specific monoclonal antibodies on both the identification and classification of leishmanial parasites were also confirmed, using in parallel isoenzyme electrophoresis (including numerical zymotaxonomic analyses) and other molecular techniques such as analysis of restriction enzyme digestion patterns of kinetoplast DNA and molecular karyotypes (Grimaldi et al. 1991, 1992, Hashiguchi et al. 1991, Kreutzer et al. 1991, Bonfante-Garrido et al. 1992, Yoshida et al. 1993, Cupolillo et al. 1994). Leishmania promastigotes were cultured in Schneider's Drosophila Medium (Gibco, Grand Island, NY) (Hendricks et al. 1978) supplemented with $10 \%$ heat-inactivated fetal calf serum (Flow Laboratories, McLean, VA) at $24^{\circ} \mathrm{C}$. Parasites in the log phase of growth were harvested by centrifugation $\left(1,500 \mathrm{x} \mathrm{g}\right.$ for $10 \mathrm{~min}$, at $\left.4^{\circ} \mathrm{C}\right)$ and washed twice in phosphate-buffered saline (PBS), $\mathrm{pH}$ 7.3. The final pellet was used for preparation of samples for parasite characterization using monoclonal antibodies (Grimaldi et al. 1987).

\section{RESULTS AND DISCUSSION}

Some preliminary results on the reactivity of monoclonal antibodies derived for selected species complexes of Leishmania (McMahon-Pratt et al. 1982, 1985, 1986, Jaffe \& McMahon-Pratt 1983, Jaffe et al. 1984, Shaw et al. 1986, Pan \& McMahon-Pratt 1988, Hanham et al. 1990) were confirmed in our recent studies using a large sample (1,500 Leishmania stocks, isolated from humans and a variety of mammalian and sandfly hosts) from different localities in the New World. Included are results of our work as well as data from other recently published studies (Grimaldi et al. 1987, 1989, 1991, Aguilar et al. 1989, Barral et al. 1991, Darce et al. 1991, Falqueto et al. 1991, Hashiguchi et al. 1991, Kreutzer et al. 1991, Ponce et al. 1991, Bonfante-Garrido et al. 1992).

Qualitatively, the reactivity of the monoclonal antibodies did not show any variation related to time in culture, culture media, or parasite virulence (Grimaldi et al. 1987). However, variation in the sensitivity of the test may occur due to the type of screening assay used (i.e., immunofluorescence, RIA or the ELISA technique). As an exemple, the $L$. donovani group-specific epitope recognized by monoclonal antibody $\mathrm{D} 2$, using RIA (Jaffe et al. 1984, Grimaldi et al. 1987) or ELISA, is weakly detected by IFA. However, as indicated in previous studies (McMahon-Pratt et al. 1986, Grimaldi et al. 1987, 1991, Barral et al. 1991), independent of the origin of Leishmania stock (i.e., host species involved or the clinical state of the infection) or of geographic area of isolation, some of the monoclonal antibodies showed a high and consistent qualitative specificity at a species level. In these analyses (see Table), the following monoclonals were the most specific: D2 (LXXVIII, 2E5-A8) for $L$. (L.) chagasi; B11 (VII-5G3-F3) for $L$. (V.) panamensis; B18 (XIV-2A5-A10) for L. (V.) braziliensis; M3 (IX-5H9-C10) for $L$. (L.) amazonensis; and V1 (CLXXVI-3C11-F14) for $L$. (L.) venezuelensis. However, significant differences between the reactivity patterns with specific monoclonal antibodies could be observed among stocks from certain species complexes of Leishmania from distinct endemic areas. These differences can be related with strain variation in the level of expression of certain antigenic determinants, as recognized by some of the monoclonal antibodies. For instance, Venezuelan isolates of $L$. (V.) braziliensis showed a distinct profile (Bonfante-Garrido et al. 1992) when they were compared with the same parasite species which circulates in Bolivia, Brazil or Colombia (Barral et al. 1991, Grimaldi et al. 1991, Grimaldi \& McMahon-Pratt, unpublished data). Also, the species-specific epitope recognized by monoclonal antibody B19 (XLIV-5A2-B9) (Grimaldi et al. 1987) could not be detected in some variant strains of $L$. (V.) guyanensis (Grimaldi et al. 1991), indicating that they had lost the epitope. In addition, some $L$. (V.) braziliensis isolates from the Brazilian Amazon Region (Grimaldi et al. 1991), as well as other variant strains of this parasite from Bolivia and Peru (Grimaldi \& McMahon-Pratt, unpublished data) did not react with the specific monoclonal antibody B16 (XIII-3E6-B11) that identify this species (Shaw et al. 1986, McMahon-Pratt et al. 1986, Grimaldi et al. 1987, Barral et al. 1991). Furthermore, although naturally occurring hybrid parasites ( $L$. (V.) braziliensis $\mathrm{x} L$. (V.) guyanensis) from Venezuela reacted with the specific monoclonal antibodies (B16 and B18) for L. (V.) braziliensis (Bonfante-Garrido et al. 1992, Grimaldi \& McMahon-Pratt, unpublished data), conflicting results were obtained when the $L$. $(V$.) braziliensis $\mathrm{x} L$. (V.) panamensis hybrids from Nicaragua were analyzed by the same method (Darce et al. 1991). Indeed, these monoclonals as 
well as the $L$. (V.) panamensis-specific monoclonal antibody (B11) did not react with the later hybrid isolates, indicating that they had lost the epitopes specific to both the parental species (Momen et al. 1993). On the other hand, numerical analysis of the enzymic profiles of $L$. (L.) venezuelensis isolates showed that this species was phenetically closely related to the WHO $L$. (L.) mexicana reference strain. However, these strains did not react with any of the monoclonal antibodies group-specific for L. mexicana complex parasites, other than the species-specific (V1) monoclonal antibody (Bonfante-Garrido et al. 1992).

As aforementioned, not all known species of Leishmania are recognized by a distinct/specific monoclonal antibody (Grimaldi et al. 1987, 1991, 1992, Kreutzer et al. 1991). However, the patterns observed with the less specific monoclonals (as defined by either qualitative or quantitative reactions with the expressed antigens) are indicative of these species. For example, monoclonal antibodies B3 (VI-4D10-D12) and B12 (XIII-3H6A12) were found to be useful in the confirmation of $L$. (V.) braziliensis from Argentina, Bolivia, Brazil, Colombia, Nicaragua and Peru (Grimaldi et al. 1987, Barral et al. 1991, Grimaldi \& McMahon-Pratt, unpublished data) or $L$. (V.) panamensis from Colombia, Costa Rica, Ecuador, Honduras and Nicaragua (Grimaldi et al., 1987 Grimaldi \& McMahon-Pratt, unpublished data). In contrast, these monoclonals were not reactive in RIA tests with stocks of $L$. (V.) guyanensis, L. (V.) shawi, L. (V.) lainsoni, L. (V.) colombiensis or $L$. (V.) equatorensis regardless of geographic origin (Grimaldi et al., 1991, 1992, Kreutzer et al. 1991, Bonfante-Garrido et al. 1992, Grimaldi $\&$ McMahon-Pratt, unpublished data). In addition, although B4 (VI-2 A5-A4) crossreacted with $L$. (V.) panamensis, L. (V.) colombiensis and $L$. (V.) equatorensis (Kreutzer et al. 1991, Grimaldi et al. 1992), the former species could be easily distinguished using in conjunction the more specific monoclonal antibody (B11). Moreover, certain of the quantitative antigenic variations occurring betwen groups or species often exceed that detected within each of these taxonomic groups (Grimaldi et al. 1987).

There are other unusual features about leishmaniases of the New World. Although American cutaneous leishmaniasis is usually caused by parasite species belonging to the $L$. braziliensis or L. mexicana complex (Lainson \& Shaw 1987, Grimaldi et al. 1989), a few cases of the disease from Brazil (Momen et al. 1985) and Ecuador (Hashiguchi et al. 1991) have been associated with a parasite similar to the Old World $L$. (L.) major. Interestingly, these $L$. major-like parasites cross- reacted with several monoclonal antibodies (T1, XLVI-5B8-A8; T2, XLVI-4H12-C2; T3, XLVI5A5-D4; T4, LXVIII-1A4-G1; and T8, LXVII3E12-F8) (Momen et al. 1985, Hashiguchi et al. 1991) produced against members of the $L$. major or L. tropica complex (Jaffe \& McMahon-Pratt 1983). In addition, our experience would indicate the existence of a number of other leishmanial parasites circulating in the Americas [e.g., L. (V.) colombiensis; L. (L.) equatorensis; and L. (L.) venezuelensis] that also cross-reacted with the $L$. major species-specific monoclonals (Kreutzer et al. 1991, Bonfante-Garrido et al. 1992, Grimaldi et al. 1992). Work is now in progress to better define the phylogenetic relationship between these parasites and Old World L. (L.) major strains. Whatever the explanation for the existence of these L. major related parasites, the results point to caution for all researchers working with New World Leishmania isolates. We recommend that when classifying these parasites, reference strains of Old World species as well as the L. major-specific monoclonals (e.g., the monoclonal T1, XIX-2D8D7) be included for comparison.

Several monoclonal antibodies (D-2, B-4, B5, B-7, B-16, B-19, M-3, M-7, P-9, T-9) analyzed in this study were selected by the WHO Workshops and recommended for general use in the identification of Leishmania species. The analyses of strains brought by the participants of the Cali Workshop also pointed strongly to the need for the incorporation of additional monoclonals (e.g., B-3, B-11, B-12, B-18, V-1) in an expanded crosspanel. We should mention that a free "Monoclonal antibody kit" for diagnosis/identification of Leishmania species, consisting of lyophilized aliquots (100 $\mu \mathrm{l})$ of the monoclonal antibodies (titers $10^{-4}$ to $10^{-6}$ ) will be available soon; as part of the kit, a description of methods (immunofluorescence and the ELISA technique) will also be provided. Requests for the kit will be made to Dr F Modabber, World Health Organization, Geneva, Switzerland. A formal request form indicating the potential application and resources available for analyses will be requested by WHO.

In conclusion, problems related to the differentiation and identification of some leishmanial parasites were encountered using serodeme analysis with specific monoclonal antibodies, as well as when those samples were analyzed by isoenzyme characterization (Grimaldi et al. 1987, 1989, 1991). Some of these isolates represent additional new species (Grimaldi et al. 1991, 1992, Kreutzer et al. 1991) or hybrid parasites (Darce et al. 1991, Bonfante-Garrido et al. 1992) and further investigation with new monoclonal antibodies is recommended in these situations. A comparison of the 
TABLE

Radioimmune binding assay results, employing Leishmania species-or group-specific monoclonal antibodies, with representative strains of New World Leishmania species $^{a}$

\begin{tabular}{|c|c|c|c|c|c|c|c|c|c|c|c|c|c|c|}
\hline \multirow[b]{2}{*}{ Species $^{b}$} & \multirow[b]{2}{*}{ Stock Code } & \multirow{2}{*}{$\begin{array}{l}\text { Country } \\
\text { of Origin }\end{array}$} & \multicolumn{12}{|c|}{ Monoclonal antibodies ${ }^{c}$} \\
\hline & & & $\mathrm{CR}$ & D2 & B3 & B4 & B11 & B12 & B16 & $5 \mathrm{~B} 18$ & B19 & M3 & M7 & $\mathrm{V} 1$ \\
\hline L.chagasi & MHOM/BR/74/PP75 & Brazil, Bahia & 9.2 & 8.4 & & & & & & & & & & \\
\hline L.chagasi & MCAN/BR/84/C17382 & Brazil, Ceará & 8.9 & 8.3 & & & & & & & & & & \\
\hline L.chagasi & MCAN/BR/82/CCG3 & Brazil, R. Janeiro & 8.7 & 11.3 & & & & & & & & & & \\
\hline L.chagasi & MHOM/HN/85/H-25 & Honduras & 8.0 & 10.6 & & & & & & & & & & \\
\hline L.braziliensis & MHOM/BR/75/M2903 & Brazil, Pará & 14.3 & & 76.4 & & & 21.0 & 26.7 & 726.5 & & & & \\
\hline L.braziliensis & MHOM/BR/81/ALG & Brazil, R. Janeiro 1 & 13.6 & & 48.6 & & & 32.5 & 31.5 & 28.6 & & & & \\
\hline L.braziliensis & MHOM/PE/00/LH-15 & $\begin{array}{ll}\text { Peru } & 1\end{array}$ & 10.4 & & 26.4 & & & 24.8 & 13.8 & 16.8 & & & & \\
\hline L.braziliensis & MHOM/VE/76/H-9 & Venezuela & 9.6 & & & & & 25.7 & 16.6 & 15.9 & & & & \\
\hline L.braziliensis $^{d}$ & ICAR/BR/86/IM2978 & Brazil, Rondônia & 6.6 & & 5.3 & & & 32.0 & & 8.1 & & & & \\
\hline L.braziliensis $^{e}$ & MHOM/BR/88/IM3482 & Brazil, Amazonas 1 & 15.0 & & & & & 15.1 & & 4.2 & & & & \\
\hline L.braziliensis ${ }^{f}$ & MHOM/BR/88/IM3483 & Brazil, Amazonas & 5.2 & & & & & 5.0 & & 4.0 & & & & \\
\hline L.panamensis & MHOM/PA/71/LS94 & Panama & 4.0 & & 25.0 & 8.4 & 6.7 & 8.9 & & & & & & \\
\hline L.panamensis & MHOM/CR/78/ICMRT72 & Costa Rica & 6.5 & & 18.8 & 12.6 & 17.0 & 9.2 & & & & & & \\
\hline L.panamensis & MHOM/HN/79/INC-4 & Honduras & 5.2 & & 17.7 & 11.2 & 13.3 & 6.8 & & & & & & \\
\hline L.panamensis & MHOM/EC/87/G-07 & Ecuador & 7.8 & & 32.9 & 30.3 & 27.8 & 7.5 & & & & & & \\
\hline L.guyanensis & MHOM/BR/75/M4147 & Brazil, Pará & 14.4 & & & & & & & & 15.0 & & & \\
\hline L.guyanensis & MHOM/BR/88/IM3471 & Brazil, Amazonas & 4.4 & & & & & & & & & & & \\
\hline L.shawi & MCEB/BR/84/M8408 & Brazil, Pará & 12.0 & & & & & & & & & & & \\
\hline L.naiffi & MDAS/BR/78/M5169 & Brazil, Pará & 11.8 & & & & & 6.2 & & & & & & \\
\hline L.lainsoni & MHOM/BR/81/M6424 & Brazil, Pará & 13.9 & & & & & & & & & & & \\
\hline L.colombiensis & IHAR/CO/85/CL500 & Colombia & 9.4 & & & & & & & & & & & \\
\hline L.equatorensis & MHOM/EC/82/Lsp1 & Ecuador & 11.3 & & & 18.4 & & & & & & & & \\
\hline L. amazonensis & MDID/BR/87/IM3217 & Brazil, Amazonas & 8.5 & & & & & & & & & 8.6 & 4.6 & \\
\hline L.amazonensis & MPOT/EC/87/G-03 & Ecuador, Los Rios & s 6.0 & & & & & & & & & 11.3 & 11.2 & \\
\hline L.amazonensis & MTAM/EC/87/G-04 & Ecuador, Bolivar & 5.9 & & & & & & & & & 12.6 & 9.9 & \\
\hline L.amazonensis & MHOM/VE/72/L44 & Venezuela & 7.8 & & & & & & & & & 12.0 & & \\
\hline L.mexicana & MNYC/BZ/62/M379 & Belize, Cayo & 7.5 & & & & & & & & & & 26.3 & \\
\hline L.mexicana & HOM/MX/83/VADYCV & Mexico & 6.7 & & & & & & & & & & 5.4 & \\
\hline L.mexicana & MHOM/EC/88/Pautel & Ecuador, Azuay & 7.8 & & & & & & & & & & 6.6 & \\
\hline L.pifanoi & MHOM/VE/60/LtRod & Venezuela & 5.8 & & & & & & & & & & & \\
\hline L.venezuelensis & MHOM/VE/74/PM-H3 & Venezuela, Lara & 4.0 & & & & & & & & & & & 6.2 \\
\hline L.aristidesi & MORY/PA/68/GML & Panama & 13.4 & & & & & & & & & & & \\
\hline L.foratinnii & MDID/BR/77/Conch. & Brazil, São Paulo 1 & 10.0 & & & & & & & & & & & \\
\hline
\end{tabular}

$a$ : n numbers shown are the ratios (counts/min with test preparations) / (counts/min with control preparations); see text. Values $>3$ (not printed) were classed as positive

$b$ : identification also established by isoenzyme analysis

$c$ : prepared from the following hybridoma clones: CR, G2D10 (this is a cross-reactive monoclonal antibody used as positive control throughout the experiments); D2, LXXVIII-2E5-A8; B3, VI-4D10-D12; B4, VI-2A5-A4; B11, VII-II-5G3-F3; B12, XIII-3H6-A12; B16, XIII-3E6-B11; B18, XIV-2A5-A10; B19, XLIV-5A2-B9; M3, IX-5H9C10; and M7, LXVIII-1D7-B8

$d$-f: classified by numerical zymotaxonomical analysis as distinct zymodemes (IOC-32, IOC-33 and IOC-35, respectively) or strain variants of this parasite species (Cupolillo et al. 1994) 
discriminatory ability of the two typing methods for Leishmania using Simpson's index of diversity showed that serodeme analysis is more discriminating, even though the zymodeme analysis produced more groups (Cupolillo et al. 1993). The continual discovery of new leishmanial species in tropical America is, in part, a reflection of the increasingly sophisticated methods for parasite differentiation. However, it also indicates that there has been a much greater evolutionary divergence among this parasite group in the New World, compared to the Old World.

\section{REFERENCES}

Aguilar CM, Rangel EF, Garcia L, Fernandez E, Momen H, Grimaldi Jr G 1989. Zoonotic cutaneous leishmaniasis due to Leishmania (Viannia) braziliensis associated with domestic animals in Venezuela and Brazil. Mem Inst Oswaldo Cruz 84: 19-20.

Barral A, Pedral-Sampaio D, Grimaldi Jr G, Momen H, McMahon-Pratt D, Ribeiro de Jesus A, Almeida R, Badaró R, Barral-Neto M, Carvalho EM, Johson Jr WD 1991. Leishmaniasis in Bahia, Brazil: Evidence that Leishmania amazonensis produces a wide spectrum of clinical disease. Am J Trop Med Hyg 44: 536-546.

Bonfante-Garrido R, Melendez E, Barroeta S, Mejia de Alejos MA, Momen H, Cupolillo E, Grimaldi Jr G 1992. Cutaneous leishmaniasis in western Venezuela caused by infection with Leishmania venezuelensis and $L$. braziliensis variants. Trans $R$ Soc Trop Med Hyg 86: 141-148.

Cupolillo E, Grimaldi Jr G, Momen H 1993. Discriminatory ability of typing systems in Leishmania. Trans $R$ Soc Trop Med Hyg 87: 116-117.

Cupolillo E, Grimaldi Jr G, Momen H 1994. A general classification of New World Leishmania using numerical zymotaxonomy. Am J Trop Med Hyg 50: 296-311.

Darce MJ, Moran J, Palacios X, Belli A, Gomez-Urcuyo F, Zamora D, Valle S, Gantier JC, Momen H, Grimaldi Jr G 1991. Etiology of human cutaneous leishmaniasis in Nicaragua. Trans $R$ Soc Trop Med Hyg 85: 58-59.

Jaffe CL, Bennett E, Grimaldi Jr G, McMahon-Pratt D 1984. Production and characterization of species specific monoclonal antibodies against Leishmania donovani for immunodiagnosis. J Immunol 133: 440-447.

Jaffe CL, McMahon-Pratt D 1983. Monoclonal antibodies specific for Leishmania tropica. I. Characterization of antigens associated with stage- and species-specific determinants. J Immunol 131: $1987-$ 1993.

Jaffe CL, McMahon-Pratt D 1987. Serogiagnostic assay for visceral leishmaniasis employing monoclonal antibodies. Trans $R$ Soc Trop Med Hyg 81: 587594.

Falqueto A, Sessa PA, Vareja o JBM, Barros GC, Momen H, Grimaldi Jr G 1991. Leishmaniasis due to Leishmania braziliensis in Espírito Santo State, Brazil. Further evidence on the role of dogs as a reservoir of infection for humans. Mem Inst Oswaldo Cruz 86: 499-500.

Grimaldi Jr G, David JR, McMahon-Pratt D 1987. Identification and distribution of New World Leismania species characterized by serodeme analysis using monoclonal antibodies. Am J Trop Med Hyg 36: 270-287.

Grimaldi Jr G, Kreutzer RD, Hashiguchi Y, Gomez EA, Mimory T, Tesh RB 1992. Description of Leishmania equatoriensis sp. n. (Kinetoplastida: Trypanosomatidae), a new parasite infecting arboreal mammals in Ecuador. Mem Inst Oswaldo Cruz. 87: 221-228.

Grimaldi Jr G, Momen H, Naiff RD, McMahon-Pratt D, Barrett TV 1991. Characterization and classification of leishmanial parasites from humans, wild mammals, and sandflies in the Amazon Region of Brazil. Am J Trop Med Hyg 44: 645-661.

Grimaldi JrG, Tesh RB 1993. Leishmaniases of the New World: Current concepts and implications for future research. Clin Microbiol Rev 6: 230-250.

Grimaldi Jr G, Tesh RB, McMahon-Pratt D 1989. A review of the geographic distribution and epidemiology of leishmaniasis in the New world. Am J Trop Med Hyg 41: 687-725.

Hanham CA, Shaw JJ, Lainson R, McMahon-Pratt D 1990. Production of a specific monoclonal antibody for the identification of Leishmania (Leishmania) venezuelensis. Am J Trop Med Hyg 42: 453-459.

Hashiguchi Y, Gomez EA, Coronel VV, Mimori T, Kawabata M, Furuya M, Nonaka S, Takaoka H, Alexander JB, Quizpe AM, Grimaldi Jr G, Kreutzer RD, Tesh RB 1991. Andean leishmaniasis in Ecuador caused by infection with Leishmania mexicana and L. major-like parasites. Am J Trop Med Hyg 44: 205-217.

Hendricks LD, Wodd DE, Hajduk ME 1978. Haemoflagellates: commercially available liquid media for rapid cultivation. Parasitology 76: 309316.

Kennett RH, Denis KA, Tung AS, Klinman NR 1978. Hybrid plasmacytoma production: fusions with adult spleen cells, monoclonal spleen fragments, neonatal spleen cells and human spleen cells. Curr Top Microbiol Immunol 81: 77-86.

Kohler G, Milstein C 1975. Continuos cultures of fused cells secreting antibody of predefined specificity. Nature 256: 495-497.

Kreutzer RD, Corredor A, Grimaldi Jr G, Grogl M, Rowton ED, Young DG, Morales A, McMahon-Pratt D, Guzman H, Tesh RB 1991. Characterization of Leishmania colombiensis sp. n. (Kinetoplastida: Trypanosomatidae), a new parasite infecting humans, animals, and phlebotomine sand flies in Colombia and Panama. Am J Trop Med Hyg 44: 662675.

Lainson R, Braga RR, Souza AAA, Póvoa MM, Ishikawa EAY, Silveira FT 1989. Leishmania (Viannia) shawi sp.n., a parasite of monkeys, sloths and procyonids in Amazonian Brazil. Ann Parasitol 
Hum Comp 64: 200-207.

Lainson R, Shaw JJ 1987. Evolution, classification and geographical distribution, v. 2, p. 1-120. In W Peters, R Killick-Kendrick (eds). The leishmaniasis in biology and medicine. Academic Press, London.

Lainson R, Shaw JJ 1989. Leishmania (Viannia) naiffi sp. n., a parasite of the armadillo, Dasypus novemcinctus (L.) in Amazonian Brazil. Ann Parasitol Human Comp 61: 3-9.

McMahon-Pratt D, David JR 1981. Monoclonal antibodies that distinguish between New World species of Leishmania. Nature 291: 581.

McMahon-Pratt D, Bennett E, David JR 1982. Monoclonal antibodies that distinguish subspecies of Leishmania braziliensis. J Immunol 129: 926-927.

McMahon-Pratt D, Bennett E, Jaffe CL, Grimaldi Jr G 1985. Subspecies and species specific antigens of Leishmania mexicana characterized by monoclonal antibodies. J Immunol 134: 1935-1940.

McMahon-Pratt D, Jaffe CL, Bennett E, David JR, Grimaldi Jr G 1986. Studies employing monoclonal antibodies for the analysis of the genus Leishmania Ross, 1903, p. 173-178. In Leishmania. Taxonomie et Phylogenese. Applications eco-epidemiologiques (Coll Intern CNRS/INSERM, 1984). IMEEE, Montpellier, France.

Momen H, Cupolillo E, Grimaldi Jr G 1993. Population genetics of Leishmania in the New World, p. 188-198. In AN Bhaduri, MK Basu, AK Sen, S Kumar (eds). Current trends in Leishmania research. Publications \& Information Directorate (CSIR), New Delhi, India.

Momen H, Grimaldi Jr G, Pacheco RS, Jaffe RS, McMahon-Pratt D, Marzochi MCA 1985. Brazilian Leishmania stocks phenotipically similar to Leishmania major. Am J Trop Med Hyg 34: 10761084.
Pan AA, McMahon-Pratt D 1988. Monoclonal antibodies specific for the amastigote stage of Leishmania pifanoi. I. Characterization of antigens associated with stage- and species-specific determinants. $J$ Immunol 140: 2406-2414.

Ponce C, Ponce E, Morrison A, Cruz A, Kreutzer R, McMahon-Pratt D, Neva F 1991. Leishmania donovani chagasi: New clinical variant of cutaneous leishmaniasis in Honduras. Lancet 337: 67-70.

Saravia NG, Holguin AF, McMahon-Pratt D, D'Alessandro A 1985. Agents of mucocutaneous leishmaniasis in Colombia. Am J Trop Med Hyg 34: 714-718.

Shaw JJ, Lainson R, McMahon-Pratt D, David JR 1986. Serodemes of Leishmania braziliensis braziliensis and Leishmania braziliensis guyanensis, p. 179-183. In Leishmania. Taxonomie et Phylogenese. Applications eco-epidemiologiques (Coll Intern CNRS/ INSERM, 1984). IMEEE, Montpellier, France.

Silveira FT, Shaw JJ, Braga RR, Ishikawa E 1987. Dermal leishmaniasis in the Amazon Region of Brazil: Leishmania (Viannaia) lainsoni sp.n., a new parasite from the State of Pará. Mem Inst Oswaldo Cruz 82: 289-292.

Yoshida ELA, Correa FMA, Marques SA, Stolf HO, Dillon NL, Momen H, Grimaldi Jr G 1990. Human, canine and equine (Equus caballus) leishmaniasis due to Leishmania braziliensis $(=$ L. braziliensis braziliensis) in the South-West Region of São Paulo State, Brazil. Mem Inst Oswaldo Cruz 85: 133-134.

Yoshida ELA, Cuba Cuba CA, Pacheco RS, Cupolillo E, Tavares CC, Machado GMC, Momen H, Grimaldi Jr G 1993. Description of Leishmania (Leishmania) forattinii sp. n., a new parasite infecting opossums and rodents in Brazil. Mem Inst Oswaldo Cruz 88: 397-406. 